\title{
Estatística e Literatura: um projeto interdisciplinar sobre migraçóes e diversidade cultural
}

\author{
Cassio Cristiano Giordano* \\ Roberta Guim Miyaji**
}

Macunaíma quando voltou da sapituca foi buscar a muiraquitã e partiu na máquina bonde pra pensão. E chorava gemendo assim: - Muiraquitã, muiraquitã de minha bela, vejo você, mas não vejo ela...

Mário de Andrade (2016)

\section{Resumo}

Não é possível dissociar os temas "diversidade cultural" e "migraçôes internas e externas" da formação do povo brasileiro. Tendo em mente essa premissa e experiências anteriores de trabalho em conjunto, dois professores - um de Matemática e uma de Língua Portuguesa - ministraram aulas simultaneamente, com uma frequência semanal de duas aulas de cinquenta minutos cada uma, para duas turmas de alunos de terceira série do ensino médio, compartilhando o mesmo espaço físico e explorando intersecçóes entre as respectivas disciplinas. Ambos elaboraram um projeto interdisciplinar que abarcou os temas "migraçóes internas e externas". Estudos sobre Estatística, Literatura do Modernismo Brasileiro e sobre o gênero textual "relato" foram realizados nas aulas e culminaram em um produto final, que foi dividido em dois dias náo consecutivos: no primeiro, foram apresentados uma dança circular, um painel sobre Estatística e uma premiação para os alunos que escreveram os melhores relatos sobre migraçóes internas e externas; no segundo dia, apresentou-se um painel contendo dados estatísticos sobre assuntos escolhidos pelos próprios alunos. $\mathrm{O}$ objetivo maior do trabalho foi explorar as intersecçóes entre os componentes curriculares acima, considerados táo diferentes, embora complementares. Os temas transversais Ética e Valores, e a importância da diversidade cultural de nosso país foram explorados durante todo o processo.

Palavras-chave: Educação Estatística, Literatura Brasileira, Interdisciplinaridade.

* Mestre em Educação Matemática pela Pontifícia Universidade Católica de São Paulo (PUC-SP), São Paulo-SP, Brasil. Doutorando em Educação Matemática pela mesma universidade. Membro do Grupo de Pesquisa Processo de Ensino e Aprendizagem em Matemática (PEA-MAT). E-mail: ccgiordano@gmail.com.

** Bacharel em Letras: Português e Japonês; licenciada também em Letras pela Universidade de São Paulo (USP-SP); professora da rede estadual de São Paulo (SEE-SP), São Paulo-SP, Brasil. E-mail: robertashinkansen@yahoo.com.br. 
Statistics and literature: an interdisciplinary project on migration and cultural diversity

\begin{abstract}
It is not possible to dissociate the themes "cultural diversity" and "internal and external migrations" from the formation of the Brazilian people. Having in mind this premise and previous experience sofworking together, two teachers - one in Mathematics and one in Portuguese Language - taught classes simultaneously, with two classes of High School third grade students, sharing the same physi-cal space, attending two 50-minute classes per week and exploring intersections between their respec-tive disciplines. Both developed an interdisciplinary project that covered the themes "internal and ex-ternal migrations". Studies on Statistics, Brazilian Modernism Literature and the textual genre "report" were conducted in class and culminated in a final product, which was divided in two days: in the first, a circular dance, a panel on Statistics and an award for the students who wrote the best reports about internal and external migration; on the second day, there was a presentation of a panel containing sta-tistical data on subjects chosen by the students themselves. The main objective of the study was to explore the intersections between the curricular components considered as different, but complemen-tary. The cross-cutting themes Ethics and Values, and the importance of the cultural diversity of our country were explored throughout the process.
\end{abstract}

Keywords: Statistical Education, Brazilian Literature, Interdisciplinarity.

\title{
Introduçáo
}

Neste artigo apresentaremos uma experiência de trabalho colaborativo que explorou as intersecçóes entre conteúdos e práticas das componentes curriculares Matemática (Estatística e Probabilidade) e Língua Portuguesa (análise de obras do Modernismo Brasileiro e produção de textos do gênero relato). O trabalho foi desenvolvido numa escola pública paulista, onde lecionamos, e tornou-se possível graças a uma abordagem interdisciplinar, fruto de uma parceria que já dura dois anos. Durante a experiência, unimos as duas áreas citadas, tão diferentes, porém complementares, sempre buscando a aproximação entre ambas por intermédio da linguagem.

A interdisciplinaridade aqui explorada é inerente ao tema migraçóes, sendo compreendida não como mera junção de disciplinas, mas de acordo com a concepção de Fazenda (2008, p. 21): "como atitude de ousadia e busca frente ao conhecimento". Segundo Tomaz e David (2012, p. 17), essa abordagem

[...] ajudaria a construir novos instrumentos cognitivos e novos significados, extraindo da interdisciplinaridade um conteúdo constituído 
do cruzamento de saberes que traduziria os diálogos, as divergências e confluências e as fronteiras das diferentes disciplinas. Supóe-se que construiríamos, assim, novos saberes escolares, pela interação entre as disciplinas.

A implementação dessa proposta envolve diversos obstáculos, e o primeiro deles é delinear o problema a ser investigado. Como nos lembra Fazenda (2008, p. 27),

[a] pesquisa interdisciplinar somente torna-se possível [quando] várias disciplinas se reúnem a partir de um mesmo objeto, porém é necessário criar uma situação problema no sentido de Freire (1974), onde a ideia nasça da consciência comum, da fé dos investigadores no reconhecimento da complexidade do mesmo e na disponibilidade destes em redefinir o projeto a cada dúvida ou a cada resposta encontrada.

Entre os outros obstáculos, destacamos eventuais resistências dos alunos às novas abordagens didáticas, além da escassez de tempo, de espaço, de recursos materiais, de apoio da unidade escolar etc. Felizmente, na escola onde implementamos o projeto em questão, a equipe de gestão escolar incentivou o desenvolvimento das atividades, assim como os demais colegas de trabalho. Pudemos dispor de espaço adequado e recursos materiais. O problema do tempo foi resolvido com a nossa parceria, pois Língua Portuguesa e Matemática, juntas, contam com dez aulas semanais.

Nossa opção por projetos apoia-se em estudiosos como Hernández e Ventura (1998, p. 63), para quem "a organização dos Projetos de trabalho se baseia fundamentalmente numa concepção de globalização entendida como um processo mais interno do que externo, no qual as relaçóes entre os conteúdos e áreas do conhecimento têm lugar em função das necessidades" e da eficácia dessas relaçôes na solução de "uma série de problemas que subjazem na aprendizagem".

Trazendo a discussão para a área da Educação Estatística, entendemos que uma forma de explorar a interdisciplinaridade e a contextualização é a proposta de trabalho por meio de projetos de aprendizagem, como expóem Porciúncula e Samá (2015, p. 134-135):

Segundo Hernández (1998), projeto não é uma metodologia, mas uma forma de refletir sobre a escola e sua funçáo. [...] Em Fagundes, Sato e Laurindo-Maçada (1999) encontramos a proposta pedagógica de Projetos de Aprendizagem, a qual busca o engajamento dos estudantes a partir 
do que estes já sabem e de seus interesses. [...] Projetos de Aprendizagem podem ser uma estratégia pedagógica para o Letramento Estatístico.

Batanero e Díaz (2004) destacam que os projetos estatísticos motivam os alunos, o que não é alcançado pela mera resolução de exercícios descontextualizados. Essas autoras nos lembram que a Estatística é a ciência dos dados, e estes não são apenas números, mas sim números em contexto. Segundo elas, no trabalho com projetos, as tarefas a ser desenvolvidas devem ser realistas. Caracterizando o ensino e a aprendizagem por meio de projetos, Batanero e Díaz (2011) destacam ainda as principais justificativas para a inclusão de projetos em sala de aula. Para elas,

as estatísticas são inseparáveis de suas aplicaçôes, e a sua justificativa maior é a sua utilidade na resoluçáo de problemas externos à própria Estatística. A história da Estatística também mostra como ela recebe ideias e aportes de áreas muito diversas, na tentativa de resolver vários problemas [...] criando conceitos estatísticos e métodos comumente utilizados [...]. (Batanero; Díaz, 2011, p. 21-22, tradução nossa).

Segundo Machado (1993), observando as orientações presentes na Proposta Curricular do Estado de São Paulo, nota-se uma relação de complementaridade e de impregnaçáo mútua entre Língua Materna (polissêmica) e Matemática (sem ambiguidades):

A Matemática compóe com a Língua Materna um par fundamental, mas de caráter complementar: é impossível reduzir um dos sistemas simbólicos ao outro. Se uma língua se aproximar demasiadamente do modo de operar da Matemática, resultará empobrecida, e o mesmo poderia ocorrer com um texto matemático que assumisse a ambivalência, apropriada apenas à expressáo linguística. A multiplicidade de sentidos em um mesmo elemento simbólico ou combinação de elementos é própria da língua natural e é intencionalmente controlada na expressão matemática. (São Paulo, 2010, p. 33).

$\mathrm{O}$ autor considera fundamental para o ensino e a aprendizagem de Matemática o reconhecimento da complementaridade Matemática-Língua Portuguesa:

Entre a Matemática e a Língua Materna existe uma relação de impregnaçáo mútua. Ao considerar-se esses dois temas enquanto componentes curriculares, tal impregnação se revela através de um 
paralelismo nas funçóes que desempenham, uma complementaridade nas metas que perseguem, uma imbricação nas questóes básicas relativas ao ensino de ambas. (Machado, 1993, p.10).

Assim, o estudo da Língua Materna auxiliaria a aprendizagem de Matemática. Em contrapartida, Fux (2010, p.12) ressalta a importância da Matemática no estudo da Língua Materna, mais especificamente da Literatura, ao afirmar: "Unir matemática e literatura pode ser uma forma de utilizar a ciência como uma nova lógica, um novo conceito, uma nova sustentação e potencialidade da literatura [...]". O autor vai mais além, extrapolando as fronteiras desses dois campos do conhecimento humano:

A negação da escrita automática e a visão do escritor como um trabalhador de palavras, acompanhadas da utilização consciente da matemática, não almejam tanto responder aos problemas que a matemática e a literatura colocam, mas sim levantar outras questôes, sejam estruturais, sejam ficcionais. (Fux, 2013, p. 246).

No que diz respeito ao desenvolvimento de nosso projeto sobre migraçóes internas e externas, incluiu o levantamento das seguintes questóes:

- Quais os principais fluxos migratórios no Brasil ao longo de sua história?

- Quais as maiores influências dessas migraçóes sobre a nossa sociedade, de modo geral?

- Quais as principais influências dos antepassados migrantes especificamente na vida do aluno, bem como de sua família, no âmbito artístico, cultural, político, religioso etc.?

- Como os maiores problemas envolvendo o fluxo de migrantes no Brasil são retratados na literatura brasileira, em particular, no Modernismo?

\section{Objetivos}

Todas as açôes desenvolvidas nesta escola que uniram, por meio de nossa parceria, as disciplinas Língua Portuguesa e Matemática, sempre visaram o aprimoramento do domínio do aluno sobre a linguagem, quer seja na leitura, interpretação ou produção de texto. Neste projeto, especificamente, buscamos: 
- Identificar as possíveis contribuiçóes de uma abordagem por meio de projetos interdisciplinares para a aquisição e aplicação do conhecimento de Estatística e para o reconhecimento do estilo literário e de autores do Modernismo Brasileiro que trataram, direta ou indiretamente, do tema migraçóes internas e/ou externas.

- Estimular os alunos a produzir conhecimento por meio do desenvolvimento do Ciclo Investigativo de Pesquisa e, com isso, adquirir autonomia.

- Aprimorar as habilidades de letramento (estatístico, no caso da disciplina de Matemática, e nas modalidades oral e escrita em Língua Portuguesa).

- Explorar os temas transversais Ética e Valores, tendo em vista a diversidade cultural na formação do povo brasileiro.

\section{Procedimentos metodológicos}

A unidade escolar, de ensino fundamental II e médio, onde este projeto foi realizado está situada na periferia de Santo André, na região do Grande ABC-SP, polo da indústria metalúrgica paulista. Ela conta com cerca de oitocentos alunos, matriculados em dois períodos: matutino e vespertino. Os alunos envolvidos no projeto aqui relatado estudam no período matutino.

Muitos dos alunos dessa escola, no entanto, não são moradores do bairro. Eles vêm de outros bairros, e até mesmo de municípios vizinhos, buscando um ensino público de qualidade. Afinal, a escola conta com um histórico de bons resultados nas avaliaçóes externas, como o Sistema de Avaliação de Rendimento Escolar do Estado de São Paulo (Saresp) e o Enem, além de apresentar índices relativamente altos de aprovação nos vestibulares da região.

Os sujeitos da pesquisa foram alunos provenientes de duas turmas da terceira série do ensino médio da referida escola estadual paulista, e, pelo caráter homogêneo das turmas, elas serão tratadas como um caso único. A atividade transcorreu durante o terceiro bimestre letivo de 2016, durante duas aulas semanais ministradas no anfiteatro da escola, de cinquenta minutos cada uma. 
Para motivar os alunos, foram apresentados vídeos, músicas, fotos, textos literários (poesia, prosa, contos, crônicas, relatos, textos jornalísticos etc.) e dados estatísticos (medidas de tendência central, medidas de dispersão, tabelas, gráficos etc.) sobre o tema. Houve, inclusive, um incentivo para que os alunos refletissem sobre as suas origens, isto é, sobre os países de seus ascendentes, e pesquisassem sobre cultura, costumes e outras particularidades desses países. Também lhes foi solicitada uma pesquisa com a família sobre sua árvore genealógica, se possível documentada por fotos, vídeos, cartas, recortes de jornais e revistas, cartôes etc.).

Em Língua Portuguesa, os alunos seguiram as instruçóes abaixo para elaborar os relatos:

1)Entrevistar uma pessoa (de preferência um familiar ou alguém pertencente ao seu círculo de amizades) que possa relatar uma experiência própria sobre migração interna e/ou externa;

2)Elaborar um breve perfil do entrevistado, respeitando seu anonimato;

3) Redigir um relato em uma página (de vinte a trinta linhas digitadas, aproximadamente), respeitando a norma culta da língua (concordância, colocação pronominal, pontuação, ortografia etc).

Em Matemática, os alunos foram confrontados com os seguintes questionamentos e orientaçóes:

Vocês conhecem bem suas origens? Conseguem esboçar sua árvore genealógica? De onde vieram seus pais? E seus avós e bisavós? A nacionalidade e etnia deles afeta diretamente seus valores pessoais? Contribui, de alguma maneira, para a estruturação de sua personalidade? Como as diversas origens afetam nossa cultura? Quais as contribuiçóes dessas origens para a culinária, moda, religião, dança, música, costumes, tradiçôes, comemoraçôes locais, regionais e nacionais, estrutura sociopolítica, econômica e jurídica etc? Quais as contribuiçôes para nossa literatura?

Vocês realizarão uma pesquisa piloto sobre esse tema. Podem começá-la formando grupos, de até cinco alunos. Cada grupo deverá entrevistar dez pessoas. O planejamento da pesquisa acontecerá na sala de aula, sob a orientação do professor. Os grupos definirão, cada um, sua questão de pesquisa, levantando hipóteses e apontando objetivos gerais e específicos. Construirấo 
um instrumento de coleta de dados contendo de dez a vinte questóes, preferencialmente objetivas, já incluindo questóes socioeconômicas, tais como renda familiar, escolaridade e religião. Estabelecerão estratégias de amostragem e realizarão a coleta, tabulaçáo e organização dos dados, que serão representados por meio de medidas de tendência central e dispersáo, tabelas e gráficos. Analisarão ainda esses dados, testarão as hipóteses e tecerão suas consideraçôes finais. Por fim, divulgarão os resultados da pesquisa para professores e alunos das demais salas, utilizando, para isso, um painel localizado no anfiteatro da escola.

Durante todo o processo, os grupos contarão com o auxílio dos professores de Língua Portuguesa e Matemática.

O painel supracitado respeita os critérios apresentados por Severino (2007), e o desenvolvimento do projeto está de acordo com os fundamentos estabelecidos para o Ciclo Investigativo de Pesquisa (Figura 1), de Guimarães e Gitirana (2013):

Figura 1 - Ciclo investigativo de pesquisa

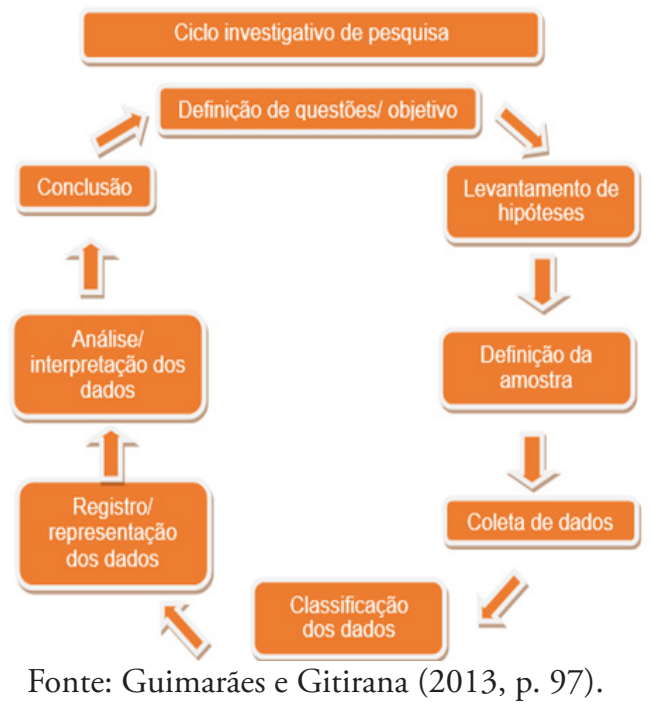

Segundo as autoras do ciclo investigativo,

é essencial uma formação estatística do estudante pautada no processo de investigação estatística. O estudante precisa adentrar no campo da 
estatística [considerando-a] como um potente instrumento para as investigaçôes com dados. Não se concebe mais uma formação estatística pautada tão somente em construir gráficos e tabelas, e calcular alguns índices sem uma inserção de todos esses instrumentos e conceitos estatísticos em contextos em que a estatística tenha o seu sentido e utilização. (p.126).

Sobre a Estatística, Toledo e Ovalle (2005, p. 13) ressaltam que sua utilização

é cada vez mais acentuada em qualquer atividade profissional da vida moderna. Nos seus mais diversificados ramos de atuação, as pessoas estão frequentemente expostas à Estatística, utilizando-a com maior ou menor intensidade. Isto se deve às múltiplas aplicaçóes que o método estatístico proporciona àqueles que dele necessitam.

Foi de extrema importância para o aluno compreender a produção do conhecimento estatístico e a experiência de participar de todas as etapas do Ciclo Investigativo de Pesquisa. Batanero e Díaz (2004, 2011) defendem a ideia de que o aluno deve, sempre que possível, escolher o tema da pesquisa. Neste caso, entretanto, não foi possível, pois esperávamos contemplar alguns objetivos curriculares do programa de Língua Portuguesa. Contudo os estudantes tiveram total liberdade para formular questóes de pesquisa, traçar objetivos e elaborar o instrumento de coleta de dados, de acordo com as características culturais e os povos que escolheram.

Esses últimos passos norteiam o levantamento de hipóteses que, por sua vez, são retomadas na fase de consideraçóes gerais/conclusóes. A definição de critérios e procedimentos de amostragem e, sobretudo, a coleta de dados permitem que o aluno vivencie o papel de pesquisador. Etapas como a de análise são mais profundas e complexas, mas é notável a importância que o aluno dá à experiência de ir a campo colher dados, e isso sempre reaparece de forma emocionada na socialização da pesquisa, em nosso caso, no painel.

As etapas em que a Matemática se faz mais presente são a de representação e a de análise dos dados. Nessas fases a orientação do professor é mais cobrada, tanto no que diz respeito a dúvidas técnicas sobre os cálculos e a elaboração de tabelas e gráficos, quanto na utilização das tecnologias digitais - neste caso, planilhas eletrônicas, calculadoras e softwares/aplicativos estatísticos nos notebooks, tablets e smartphones, com destaque para o Excel e o GeoGebra. No final, após a representação e a análise dos dados, a divul- 
gação dos resultados das pesquisas deve ser valorizada, pois não há sentido algum em produzir conhecimento científico e não socializá-lo. Neste caso, a comunidade escolar pode ter acesso aos resultados por meio do painel.

Tratando especificamente da disciplina de Língua Portuguesa, destacamos uma observação sobre contextualização e interdisciplinaridade, extraída da Proposta curricular do estado de Sáo Paulo:

Deve-se levar em conta, em primeiro lugar, que os alunos se apropriam mais facilmente do conhecimento quando ele é contextualizado, ou seja, quando faz sentido dentro de um encadeamento de informaçóes, conceitos e atividades. Dados, informaçóes, ideias e teorias não podem ser apresentados de maneira estanque [...]. A questão da contextualização remete-nos à reflexão sobre a intertextualidade e a interdisciplinaridade. De que maneira cada objeto cultural se relaciona com outros objetos culturais? Como uma mesma ideia, um mesmo sentimento e uma mesma informação são tratados pelas diferentes linguagens? (São Paulo, 2010b, p. 39, grifo nosso).

Para justificar a integração entre Literatura (Modernismo) e produção textual (relato) no ensino médio, transcrevemos um trecho contido no mesmo documento. De acordo com esse texto, o currículo de Língua Portuguesa do estado de São Paulo pressupóe,

em todas as séries, a valorizaçáo de interfaces entre o conhecimento reflexivo de conteúdos linguísticos e literários e o cotidiano cultural em que o aluno está inserido. [...] Para esse fim, valorizam-se diferentes esferas de atividades com a linguagem, que a consideram a partir de variadas perspectivas (extra e intralinguísticas), visando a surpreendê-la em sua multiplicidade dinâmica e social. [...] A não divisão do estudo da Língua Portuguesa nas tradicionais frentes (Literatura, Gramática e Redação) [...] se dá por diferentes motivos: a) $\mathrm{O}$ texto literário, pela sua natureza, pode ser contemplado em diferentes disciplinas. A escolha, contudo, de situar o estudo literário dentro da disciplina Língua Portuguesa deve condicionar e orientar os olhares e a prática didática com tal texto [...]. b) O estudo da Língua Portuguesa, tal como aqui proposto, não é satisfatoriamente atendido na tradicional divisão em três frentes. [...] partimos sempre, em nossos estudos, de um determinado contexto sociocultural que encaminha e direciona o nosso trabalho com a linguagem. Esse mesmo contexto é também o ponto de chegada, de tal modo que o conhecimento de linguagem possa, efetivamente, propiciar a transformaçáo da realidade da qual partimos. c) $O$ processo de escrita, quando considerado em sua dinâmica social, ultrapassa as 
propostas tradicionalmente convencionais de uma aula de redação ou de produção textual. Isso porque ensinar as regras inerentes à estrutura de determinado gênero textual não é necessariamente permitir que o educando tenha uma experiência real com o processo de escrita. Escrever é uma prática social. (São Paulo, 2010b, p. 38-39).

Perceba-se, no trecho escolhido, que há o claro incentivo à integraçáo entre Literatura, Gramática e Redação, bem como à abordagem interdisciplinar.

Explorando a interdisciplinaridade entre Literatura Brasileira e Estatística, como professora de Língua Portuguesa, relacionei a leitura e análise de um gráfico do IBGE, que tratava da imigração no Brasil (Figura 2), com as obras Macunaima, o herói sem nenhum caráter, publicada originalmente em 1928 (Andrade, 2016), Amar, verbo intransitivo (Andrade, 1995) e Brás, Bexiga e Barra Funda (Machado, 1982), essas duas publicadas originalmente em 1927.

Figura 2 - Número de imigrantes que chegaram ao Brasil entre 1820 e 1975

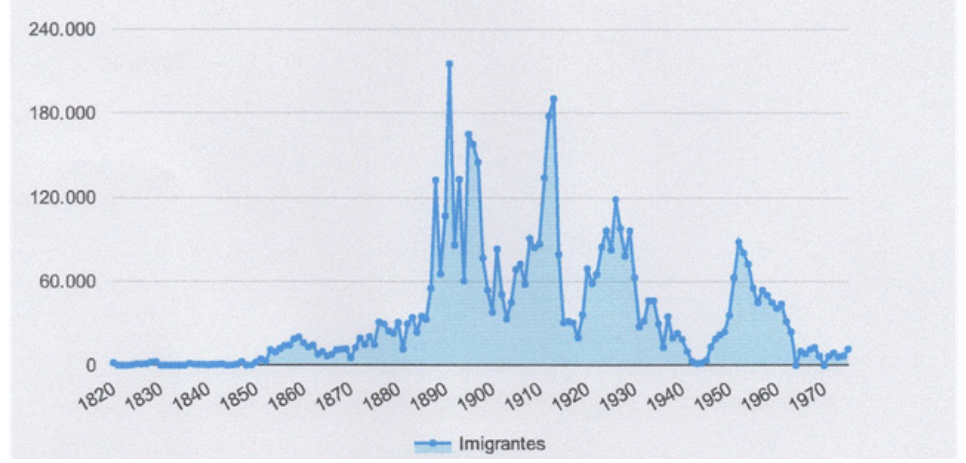

Fonte: IBGE, 2000.

Tal gráfico foi utilizado para que os alunos pudessem relacionar fatos históricos ocorridos no Brasil neste período e que mobilizaram a produção literária nacional. Percebe-se uma alta repentina na quantidade de imigrantes que entraram no país após 1888, ano da abolição da escravatura. Esse aumento ocorreu no período entre1910 e 1920, pouco antes dos 
lançamentos das obras Macunaíma, o herói sem nenhum caráter, Amar, verbo intransitivo e Brás, Bexiga e Barra Funda. A aceleraçáo da vinda de imigrantes coincidiu com o momento em que ocorrera a Primeira Grande Guerra (1914-1918), com imigrantes fugindo de uma Europa devastada. Na década de 1940, ao contrário do que acontecera antes, houve um grande decréscimo na entrada de imigrantes no Brasil. A Segunda Guerra Mundial, ocorrida naquele momento, trouxe a restrição do ingresso deles no país. $\mathrm{O}$ Brasil rompeu relaçóes diplomáticas com os países do Eixo, considerando seus cidadãos inimigos, a partir daí, alinhando-se às estratégias políticomilitares dos Aliados, sobretudo dos norte-americanos, como reforça a pesquisadora Priscilla Perazzo. Alguns estrangeiros foram enviados para presídios comuns - como os de Ilha Grande e Ilha das Flores (RJ). Contudo, a maioria foi para campos de concentração organizados pelo Ministério da Justiça, segundo Perazzo (2009).

Tais observações emergiram da discussão entre professores e alunos, que foi facilitada, por via indireta, pelas contribuiçóes de outros dois professores, de História e de Sociologia, que já haviam abordado esse tema com os alunos.

A partir daí, em Língua Portuguesa, cada grupo de alunos (de até cinco integrantes) escolheu para leitura uma das obras já citadas. Após a leitura, os grupos elaboraram, cada um, uma resenha crítica da obra escolhida, seguida por uma apresentação oral, destacando os choques culturais decorrentes dos processos migratórios ilustrados nessa obra. Considere-se que, em Macunaima, há a migração interna do protagonista e seus irmãos; em Amar, verbo intransitivo, também aparecem imigrantes no enredo: o personagem secundário Tanaka (um criado japonês) e a alemã Elza, chamada de Fräulein, que havia sido contratada para iniciar sexualmente o adolescente Carlos, filho do rico industrial Souza Costa; e em Brás, Bexiga e Barra Funda (contos), as narrativas envolvem imigrantes italianos e seus descendentes.

Sobre esta última obra, vale citar o que nos diz Bosi (1994, p. 423):

Voltado para a vida de sua cidade, Alcântara Machado soube ver e exprimir as alteraçôes que trouxera à realidade urbana um novo personagem: o imigrante. $\mathrm{O}$ enxerto que o estrangeiro, sobretudo o italiano, significava para o tronco luso-tupi da antiga Sáo Paulo, produzira mudanças de costumes, de reaçóes psicológicas e, naturalmente, uma fala nova a espelhar os novos conteúdos. E nos contos de Brás, Bexiga e Barra Funda que vão encontrar exemplos de uma ágil literatura citadina, realista (aqui 
e ali impressionista), que já não se via desde os romances e sátiras cariocas de Lima Barreto. Mas, ao contrário do que se dava com este "humilhado e ofendido", há muito de divertissement nas páginas do paulistano. Nelas, uma análise ideo-estilística mais rigorosa não constata nenhuma identificação coerente com o imigrante, "pitoresco" no máximo, patético porque criança (o conto célebre do Gaetaninho), mas em geral, ambicioso, petulante, quando capaz de competir com as famílias tradicionais em declínio. O populismo literário é ambíguo: sentimental, mas intimamente distante. No caso do talentoso Alcântara Machado, é sensível, a uma leitura crítica dos contos, esse fatal olhar de fora os novos bairros operários e de classe média a crescerem e consolidarem uma nova S. Paulo, que ignorava a vetusta Academia de Direito e nada sabia dos salóes que acolheram, antropofagicamente, os homens de 22.

Concluída esta atividade de literatura, houve uma proposta de redação - gênero relato - sobre migrações internas ou externas. Na execução dessa tarefa, os alunos procuraram uma pessoa de seu círculo social (familiares, amigos, colegas de estudos ou de trabalho), presencialmente ou por meio das redes sociais, para uma entrevista aberta. Seguiu-se à entrevista um relato escrito obedecendo à norma padrão da língua: um relato coerente, coeso e com a menor quantidade de desvios gramaticais. Aqueles que redigissem as narrativas mais emocionantes receberiam um certificado, expedido pela escola, na data da apresentação do painel já mencionado neste artigo, além de ganharem nota extra nos componentes curriculares Língua Portuguesa e Matemática.

Tal multiplicidade de tarefas buscou proporcionar aos alunos o desenvolvimento de habilidades de letramento. Nos termos de Soares (2003, p. 95), o letramento é

um contínuo, mas um contínuo não linear, multidimensional, ilimitado, englobando múltiplas práticas, com múltiplas funções, com múltiplos objetivos, condicionados por e dependentes de múltiplas situaçôes e múltiplos contextos, em que consequentemente são múltiplas e muito variadas as habilidades, conhecimentos, atitudes de leitura e de escrita.

Os alunos do primeiro ano do ensino médio, aos quais a professora de Língua Portuguesa estava ministrando aulas desde março de 2016, foram convidados a participar do projeto. Orientados pelas professoras de Arte e Língua Portuguesa, eles elaboraram uma dança circular temática. 
$\mathrm{Na}$ última aula anterior ao painel, no anfiteatro da unidade escolar, onde se reuniram os alunos das terceiras séries do ensino médio, foi lido o poema "Auto-retrato aos 56 anos" (Ramos, 1948). Propôs-se aos alunos escrever e apresentar, oralmente, um poema sobre si mesmos, com estrutura similar à do poema de Graciliano Ramos e cujo tema fosse uma reflexão a respeito de si próprios e de suas origens. Ao final, houve uma discussão sobre o autor e sua obra-prima, Vidas secas (Ramos, 2003), estudada no primeiro bimestre e que também aborda a questão da migração brasileira, particularmente dos retirantes nordestinos (Fabiano, Sinhá Vitória, os dois filhos e a cachorra Baleia).

\section{Resultados}

Os alunos apresentaram o produto final das propostas de atividades em dois dias náo consecutivos, para membros da equipe de gestáo escolar, professores, demais funcionários e alunos de outras turmas.

No primeiro dia, foram realizadas as seguintes atividades: exposição, por meio de cartazes, da pesquisa estatística sobre a migração interna e/ou externa no Brasil; apresentação da dança circular dos alunos do primeiro ano; promoção de uma "pista de dança" para alunos e visitantes do evento, com músicas brasileiras voltadas à temática dos povos que participaram mais ativamente dos movimentos migratórios, interno e externo, no Brasil. Essas músicas podem ser ouvidas por meio do link <https://www.youtube. com/playlist?list=PLbHQKePPs-zlbCbJxdsdlYItbk7OHegbF>. Nele, além de cançóes internacionais, como as dos cantores italianos Laura Pausini e Gianluca Grignani, há músicas populares que remetem à ideia de terra natal/retorno às origens, tais como "Quijote", do espanhol Julio Iglesias, "Canção do mar", da portuguesa Amália Rodrigues, e "Furusato", do cantor japonês Hiroshi Itsuki.

Para finalizar o primeiro dia, houve a premiação dos alunos (melhor redação e relato mais emocionante), com entrega de certificados. As produçôes escritas contempladas foram: "De um pé de café" (melhor redação), e "A vinda ao Brasil" (relato mais emocionante). No primeiro texto, uma aluna relatava as origens de seu pai, que havia migrado de uma roça de Rinópolis a São Paulo, e, no segundo, um aluno falava das origens de seu avô português, que passara parte da infância no orfanato por ter sido fruto do relacionamento entre um homem casado e uma viúva com cinco filhos. 
No segundo dia, ocorreu o painel de estatística, com a apresentação oral dos resultados da pesquisa de campo realizada pelos alunos. A pesquisa foi apresentada para professores e alunos de outras turmas.

Também na Estatística, houve a premiação dos melhores relatos escritos, considerando-se o mesmo critério: aquele(a) que escrevesse a melhor redaçáo (texto coerente, coeso, com o menor número de desvios gramaticais) e aquele(a) que redigisse o relato mais emocionante receberiam o certificado de menção honrosa, além de um ponto a mais na média daquele bimestre.

Nos textos redigidos, os nomes de familiares ou amigos retratados não deveriam ser revelados, podendo ser substituídos por nomes fictícios. A seguir, destacamos a introdução de alguns relatos:

"Neste relato, irei contar a vida de uma senhora já falecida no dia 25 de dezembro de 2003. Nascida no Rio de Janeiro, noninha levava uma vida difícil" (Aluna V. M. G., finalista em "relato emocionante"). Percebe-se, no fragmento, que a estudante, além de ter obedecido fielmente à proposta de não mencionar o nome da avó, isto é, a "noninha", conseguiu imprimir com facilidade o sentimento de ternura para com a pessoa de quem estava falando.

"Este trabalho faz parte do projeto interdisciplinar de português/matemática, este relato foi baseado em uma história real, porém foram feitas algumas alteraçôes nos nomes dos personagens [...]" (Aluno I. V., vencedor da categoria mencionada acima). Não era obrigatório constar, na introdução, nenhum comentário sobre a ocultaçáo dos nomes, mas aqui cabe uma hipótese: provavelmente, o aluno julgou relevante ressaltar a importância de trocar os nomes dos envolvidos.

"O texto fala sobre a vida de um cearense chamado Marco, que por causa dos sofrimentos que sua família passava teve que fazer uma Migração Interna, ou seja, teve que sair de sua terra natal para ir para outra terra onde passou também muitas dificuldades, mas conseguiu superar todas e seguir em frente" (Aluno C. H. O. A., finalista da "melhor redação"). Embora a introdução de C. H. O. A. contenha algumas partes que podiam ser corrigidas (duplicidade das palavras "terra" e "para", por exemplo), ela é bem clara quanto às informaçôes solicitadas na proposta de escrita.

Destacamos, também, alguns trechos significativos na parte do desenvolvimento dos relatos, começando pelo texto escrito por C. M., vencedora da categoria "melhor redação": "Um dia, minha mãe escutou a cachorra latindo demais e meu pai cismou que tinha algo de errado, eles saíram 
correndo para ver o que era, quando viram uma cobra que estava prestes a me atacar por querer o leite que estava comigo. A cachorra avançou nela, afugentando-a." No trecho, nota-se a atenção aos detalhes das memórias do entrevistado, que demonstra lembrar-se claramente da cena da cobra prestes a atacá-lo.

O aluno V. I., vencedor da categoria "relato emocionante", expressou a situação do imigrante português entrevistado desta maneira:

Nasci órfăo, mas quando cresci descobri que tinha uma grande história por traz [sic] de tudo isso. Minha máe Maria ficou viúva antes de eu nascer, eu era o caçula dos meus cinco irmãos, porém eu não tinha o mesmo sangue que eles, pois minha mãe depois de ficar viúva, se envolveu com um homem casado que se chamava João. Minha mãe estava desesperada pois estava desempregada e com cinco filhos para criar, meu pai João também não podia ficar comigo pois era casado. Assim que nasci minha mãe me colocou em um orfanato, e foi lá que eu fiquei até os meus 6 anos de idade recebendo visitas dos meus pais mensalmente. Quando a guerra estava no auge, meu pai ficou desempregado e resolveu ir para o Brasil, porém ele não poderia ir se não tivesse um filho e sua esposa Benedita não tinha gerado nenhum filho ainda. Então, meu pai resolve me adotar sem revelar para a esposa que eu era o seu filho. Essa mentira obviamente não durou por muito tempo, ela acabou descobrindo e fez um papel de madrasta má me contando toda a verdade. Antes de chegar ao Brasil passamos terríveis momentos em um porão de um navio durante quatro meses, enfrentei diversas enfermidades e passamos fome.

Comparando a redação do vencedor V. I. com a da vencedora C. M., constata-se facilmente que ele comete uma série de desvios gramaticais, como, por exemplo, erros ortográficos ("por traz"), pontuação inadequada (ausência de vírgulas após adjunto adverbial) e repetição de palavras ("minha mãe", "meu pai"). No entanto, é inegável que há em seu relato um impressionante retrato de um drama familiar - um filho gerado em uma relação extraconjugal e enviado a um orfanato, passando, mais tarde, a viver com o pai, que, para isso, tenta enganar a esposa. Ao descobrir o fato, ela faz o "papel da madrasta má", contando toda a verdade ao enteado. Foi este aspecto que fez que o aluno fosse escolhido.

Vale também destacar certos aspectos de outras redaçóes. Alguns alunos compreenderam que utilizar-se de recursos como a ironia era mais do que permitido: "Quando cheguei lá, fui 'muito bem recebida' e logo advertida para que soubesse que deveria ajudar com as despesas de casa, afinal, 
eu era mais uma boca para alimentar" (Aluna J. R. P., finalista da categoria "melhor redação").

A estudante acima, ao escrever o texto "Cabeleireira de mão cheia", fez um relato sobre uma moça que, ao sair do Ceará, sofre com a situação de ter de morar com o tio em Moji das Cruzes.

A finalista C. T. ("relato emocionante") não pensou duas vezes para inserir críticas a fatos históricos:

Há muito tempo atrás [sic], o Japão estava muito populoso, entáo o governo começou a falar para a população que no Brasil estava fácil para ganhar dinheiro. [...] Já minha mãe também foi enganada pelo governo e veio trabalhar no Brasil. Na viagem ela viu muita gente morrendo e sendo jogada no mar, pois não havia como enterrar, isso só acontecia porque não havia médicos para tentar salvar essas pessoas.

De modo geral, percebemos sensível melhora na produção escrita desses alunos quando convidados a abordar um tema sobre o qual haviam investigado e que, portanto, conheciam melhor. Essa afirmação é válida tanto para as produçóes textuais baseadas em pesquisa bibliográfica quanto para os relatos ligados à pesquisa de campo, no caso da Estatística. O progresso foi visível também no caso do relato envolvendo uma pessoa querida, categoria que mobilizava tantas emoçóes.

\section{Consideraçóes finais}

Acreditamos que a abordagem por meio de projetos interdisciplinares ofereça amplas possibilidades de exploração de letramento, tanto para a Língua Portuguesa quanto para a Matemática.

Além de possibilitar o desenvolvimento das habilidades de letramento, a realização deste projeto permitiu promover autonomia nos alunos. Para a maioria deles, o trabalho com o ciclo investigativo de pesquisa foi a primeira experiência de realização de pesquisa estatística, bem como a primeira oportunidade de apresentação de trabalho em formato painel.

Este projeto também tornou possível relacionar textos literários e dados estatísticos, contextualizando historicamente o momento da produção desses textos, conforme orienta o Currículo do estado de Sáo Paulo... (São Paulo, 2010a). Finalmente, contribuiu para criar um ambiente propício à 
convivência e à tolerância, considerando os temas transversais Ética, Valores e Pluralidade Cultural.

Esperamos, com a divulgação desta experiência, estimular a realização de novas investigaçóes que busquem aproximar os componentes curriculares Língua Portuguesa e Matemática.

\section{Referências}

ANDRADE, M. Amar, verbo intransitivo. Belo Horizonte: Villa Rica, 1995. ANDRADE, M. Macunaíma, o herói sem nenhum caráter. São Paulo: Companhia das Letras, 2016.

BATANERO, C.; DÍAZ, C. El papel de los proyectos en la enseñanza y aprendizaje de la estadísti-ca. In: ROYO, J. P. (Ed.). Aspectos didácticos de las matemáticas. Zaragoza-Espańa: ICE, 2004. p. 125-164.

BATANERO, C.; DÍAZ, C. Estadística con proyectos. Granada-España: Ed. Universidad de Gra-nada, 2011.

BOSI, A. História concisa da Literatura Brasileira. São Paulo: Cultrix, 1994. BRASIL. IBGE. 500 anos de povoamento. Rio de Janeiro, 2000. Disponível em:<http://brasil500anos.ibge.gov.br/estatisticas-do-povoamento/ imigracao-total-periodos-anuais.html>. Acesso em: 2 fev. 2017.

FAZENDA, I. (Org.). O que é interdisciplinaridade. São Paulo: Cortez, 2008.

FIORENTINI, D.; LORENZATO, S. Investigação em educação matemática: percursos teóricos e metodológicos. 2. ed. rev. Campinas: Autores Associados, 2007.

FUX, J. A matemática em Georges Perec e Jorge Luis Borges: um estudo comparativo. Tese (Doutorado) - Universidade Federal de Minas Gerais, Belo Horizonte, 2010.

FUX, J. Literatura e matemática: Jorge Luis Borges, Georges Perec e o Oulipo. KBR Editora Digital, 2013.

GUIMARÃES, G.; GITIRANA, V. Estatística no ensino fundamental: a pesquisa como eixo estruturador. In: BORBA, R. E. S. R.; MONTEIRO, 
C. E. F. Processos de ensino e aprendizagem em Educação Matemática. Recife: Ed. UFPE, 2013.

HERNANDEZ, F.; VENTURA, M. A organização do currículo por projetos de trabalho. Porto Alegre: Artmed, 1998.

LAFETÁ, J. L. Mário de Andrade: literatura comentada. São Paulo: Nova Cultural, 1988.

MACHADO, A. A. Brás, Bexiga e Barra Funda. São Paulo: Facsimilar, 1982.

MACHADO, N. J. Matemática e língua materna. 3. ed. São Paulo: Cortez, 1993.

MACHADO, N. J. Educação: projetos e valores. 5. ed. São Paulo: Escrituras, 2004

NASSIF, L. O Brasil também teve campos de concentração. GGN, o jornal de todos os Brasis, fev. 2011. Disponível em: <http://jornalggn.com.br/blog/ luisnassif/brasil-tambem-teve-campos-de-concentracao $>$. Acesso em: $2 \mathrm{fev}$. 2017.

PORCIÚNCULA, M.; SAMÁ, S. Projetos de aprendizagem: uma proposta pedagógica para a sala de aula de estatística. In: SAMÁ, S.; PORCIÚNCULA, M. (Org.). Educação estatística: ações e estratégias pedagógicas no ensino básico e superior. Curitiba: CRV, 2015. p. 133-141.

RAMOS, S. Auto-retrato aos 56 anos, 1948. Disponível em: <http:// graciliano.com.br/site/autorretrato/>. Acesso em: 2 fev. 2017.

RAMOS, G. Vidas secas. São Paulo: Editorial Norma, 2003.

SÃO PAULO. Currículo do estado de São Paulo: códigos, linguagens e suas tecnologias: ensino fundamental ciclo II e ensino médio. São Paulo: SE: CENP, 2010a.

SÃO PAULO. Proposta curricular do estado de São Paulo: Língua Portuguesa. São Paulo: SE; CENP, 2010 b.

SEVERINO, A. J. Metodologia do trabalho cientifico. São Paulo: Cortez, 2007.

SOARES, M. Letramento e escolarização. In: RIBEIRO, V. M. (Org.). Letramento no Brasil. Sáo Paulo: Global, 2003. p. 89-113. 
TOLEDO, G. L.; OVALLE, I. I. Estatística básica. São Paulo: Atlas, 2005. TOMAZ, V. S.; DAVID, M. M. M. S. Interdisciplinaridade e aprendizagem da matemática em sala de aula. Belo Horizonte: Autêntica, 2012.

Recebido em: 14 fev. 2017.

Aceito em: 21 mar. 2017. 